\title{
Expression of Different Calmodulin Genes in Bean (Phaseolus vulgaris L.): Role of Nod Factor on Calmodulin Gene Regulation
}

\author{
Alberto Camas, ${ }^{1}$ Luis Cárdenas, ${ }^{2}$ Carmen Quinto, ${ }^{2}$ and Miguel Lara ${ }^{1}$ \\ ${ }^{1}$ Centro de Investigación sobre Fijación de Nitrógeno, Universidad Nacional Autónoma de México, Apartado postal 565-A, \\ Cuernavaca, Morelos, México ; ${ }^{2}$ Instituto de Biotecnología, Universidad Nacional Autónoma de México, Apartado postal \\ 565-A, Cuernavaca, Morelos, México.
}

Submitted 11 July 2001. Accepted 28 January 2002.

Three calmodulin (PvCaM-1, PvCaM-2, and PvCaM-3) clones were isolated from a Phaseolus vulgaris nodule cDNA library. All clones contain the complete coding region and are 62 to $74 \%$ homologous within this region. Compared to plant CaM consensus sequences, PvCaM-2 has a novel tyrosine ${ }_{118}$ residue, representing a putative phosphorylation site. Southern analysis suggested that calmodulin is encoded by a gene family. These three CaM clones are expressed mainly in young tissues and meristems. The expression pattern of $\mathrm{PvCaM-2}$ and $\mathrm{PvCaM-3}$ is almost identical but different from that of $P v C a M-1$, suggesting that $P v C a M-1$ is a well-defined $C a M$ gene, whereas $P v C a M-2$ and $P v C a M-3$ could be alleles. PvCaM clones are expressed early in nodules, and transcript levels increase from nodule primordia to nodule-like structures induced by the Nod factor. Conversely, in roots, Nod factor lowers mRNA levels of all three PvCaM clones, but especially of PvCaM-1. Inhibition of $\mathrm{PvCaM-1}$ expression also is observed when 2,3,5-triiodobenzoic acid is added and is prevented when roots are treated with indole-3-acetic acid, suggesting that $\mathrm{PvCaM-1}$ regulation is related to the Nod factor inhibition of polar auxin transport. These results could suggest that CaM clones do not participate in the early signaling generated by the Nod factor but do participate in early events of nodule formation.

Additional keywords: auxin transport inhibition, lipochitooligosaccharide, Rhizobium etli.

Plant cells are subjected to a variety of environmental stimuli. They often respond by a rapid and transient increase in the concentration of cytosolic calcium $\left(\mathrm{Ca}^{2+}\right)$. These $\mathrm{Ca}^{2+}$ signals modulate cellular processes via high-affinity, $\mathrm{Ca}^{2+}$-binding proteins, of which calmodulin is one of the best characterized. Most $\mathrm{Ca}^{2+}$-binding proteins contain a common structure motif, the EF hand, which is a helix-loop-helix structure that binds a single $\mathrm{Ca}^{2+}$ ion (O'Neil and DeGrado 1990). Calmodulin is composed of 148 amino acids (aa) arranged in two globular domains connected with a long, flexible helix. Each globular domain contains a pair of $\mathrm{EF}$ hands. The binding of $\mathrm{Ca}^{2+}$

Corresponding author: Miguel Lara, Centro de Investigación sobre Fijación de Nitrógeno; Telephone: +52 (777) 329 1815; Fax: +52 (777) 317 5581; E-mail: lara@ cifn.unam.mx.

The nucleotide sequence data reported will appear in the GenBank sequence database under accession numbers AF03003-2 (PvCaM-1), AF030033 (PvCaM--2), and AF0330034 (PvCaM-3). drives a conformational change in the protein. In its $\mathrm{Ca}^{2+}$ bound state, calmodulin activates numerous target proteins involved in a variety of cellular processes (Ikura et al. 1992; Snedden and Fromm 1998; Zielinski 1998).

In animal systems, over 25 calmodulin targets have been identified, including kinases, receptors, ion channels, and Gproteins (Zhou and Lewis 1995). In plants, different calmodulin-binding proteins have been isolated. Among them are proteins implicated in cellular metabolism (Baum et al. 1996), phosphorylation (Ramachandiran et al. 1997; Watillon et al. 1993), ion transport (Harper et al. 1998; Malmstrom et al. 1997), cytoskeleton function (Durso and Cyr 1994; Narasimhulu et al. 1997), and DNA binding (Poovahiah and Reddy 1993; Snedden and Fromm 1998; Szymanski et al. 1996).

One of the intriguing properties of calmodulin is that it can bind numerous target proteins with no discernible amino acid sequence motif composing a consensus CaM-binding domain. $\mathrm{CaM}$ binds with high affinity to peptides ranging from 17 to 25 aa in length with positive charge characteristics, having a basic amphiphilic $\alpha$-helical structure. Several reports have documented that $\mathrm{Ca}^{2+}$ signals are perceived by $\mathrm{CaM}$ acting in concert with its target protein (Line and Forsen 1995; Olwin and Storm 1985). Enhanced binding of $\mathrm{Ca}^{2+}$ by $\mathrm{CaM}$ also is observed in the presence of peptides composing the CaM binding domain of target proteins (Haiech et al. 1991). Independent of the mechanism by which $\mathrm{CaM}$ binds target proteins, the complex interplay between $\mathrm{Ca}^{2+}, \mathrm{CaM}$, and target proteins can account for a significant portion of the diversity attributed to CaM-mediated signal transduccion.

In addition, the calmodulin multigene family, composed of several genes, has been described in many plant species. In wheat, seven genes encode the conserved calmodulin TaCaM-I and two other genes encode TaCaM-II, which differs from TaCaM-I in just two conserved amino acid substitution (Yang et al. 1998). In Arabidopsis spp., four CaM isoforms that differ from one another by as many as six amino acid substitutions were found (Gawienowski et al. 1993). It also was shown that the mRNAs encoding these CaM proteins are differentially expressed, suggesting a particular role for each isoform. In this respect, CaM mRNAs are known to be developmentally regulated and signal responsive (Botella and Arteca 1994; Braam and Davis 1990; Chen et al. 1994; Ling and Assmann 1992; Schuuring et al. 1996; Stinemetz et al. 1987).

The interaction between legume plants and rhizobia lead to the formation of a new plant organ (the nodule), where nitrogen fixation takes place. After plant inoculation with Rhizobium spp., root hair deformation occurs. The root hair tip curls upon itself; within these curled root hairs, rhizobia promote the 
formation of infection threads, which allows the invasion of the bacteria into the cortex of the root and, ultimately, the release of bacteria into membrane-enclosed compartments within the cells of the nodule. The inner cortical cell of the root immediately below the infection thread divided, eventually forming a nodule primordium (Mylona et al. 1995). During the initial step of the interaction, root-secreted flavonoids induce the expression of rhizobial nodulation genes (nod genes). The nod genes encode enzymes involved in the synthesis of lipochitooligosaccharide molecules, also termed Nod factor (Dénarié et al. 1996). Nod factors are excreted by the rhizobia and trigger root hair deformation, preinfection thread formation, cortical cell division, and nodule formation (Lhuissier et al. 2001; Reli• et al. 1994). The first event, occurring a few seconds after Nod factor application, is a $\mathrm{Ca}^{2+}$ influx leading to an increase in the cytosolic $\mathrm{Ca}^{2+}$ concentration (Cárdenas et al. 1998; Felle et al. 1998), which has been related to tip growth in root hairs (Erhardt et al. 1992, 1996; Lhuissier et al. 2001; Wymer et al. 1997). Together with $\mathrm{Ca}^{2+}$ influx, Nod factors promote a reduction in the polar auxin transport, creating a change in plant hormone physiology that precedes the formation of nodule primordia (Hirsch and Fang 1994; Hirsch et al. 1997; Mathesius et al. 1998). As well as Nod factors, direct application of cytokinins or polar auxin transport inhibitors 2,3,5-triiodobenzoic acid (TIBA) and N-(1-naphthyl)phthalamic acid induces nodulelike structures on Macroptillum atropurpureum (Reli• et al. 1993) and Medicago sativa roots (Hirsch et al. 1989). In this way, Nod factor, as well as increases in the cytokinin-auxin balance, have

A

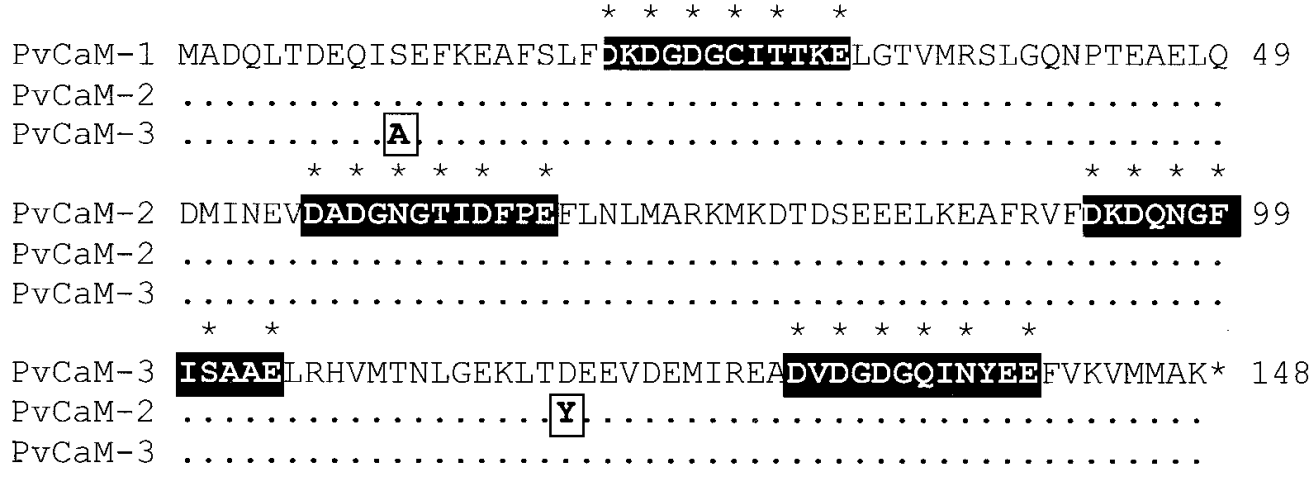

B

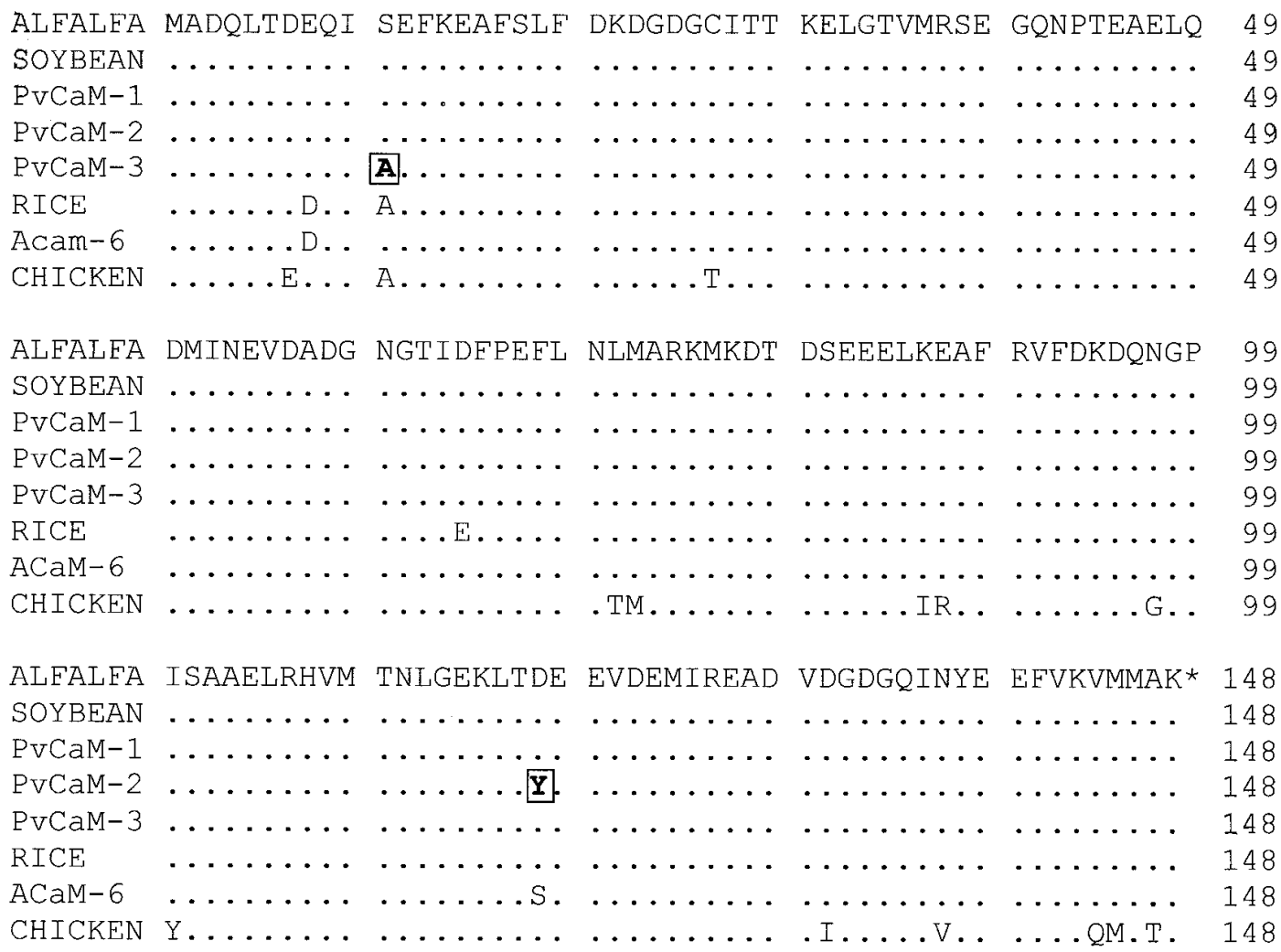

Fig. 1. Alignment of the predicted amino acid sequences of the PvCaM clones. Comparison of amino acid sequences deduced for the three Phaseolus vulgaris $\mathrm{CaM}$ clones and those of $\mathrm{CaM}$ from other plants and animals. A, Boxed residues in CaM-2 and CaM-3 isoforms indicate the two amino acid differences compared with the same position at the CaM-1 amino acid sequence. Shaded areas mark the putative EF-hand domains. Asterisks indicate the position of amino acids involved in $\mathrm{Ca}^{2+}$ binding. $\mathbf{B}$, Comparison of the deduced amino acid sequences of $P$. vulgaris calmodulins with those of calmodulin of alfalfa (Barnett and Long 1990), soybean (SCAM-1) (Hyoung et al. 1995), Arabidopsis (AcaM-6) (Gawienowski et al. 1993), rice (Liu et al. 1993), and chicken (Putkey et al. 1985). Asterisks indicate the position of the stop codons. Dots represent identical amino acid residues. 
the same effect on the formation of "pseudo-nodules." Although not produced by plants, Nod factors are in fact "hormonelike" substances.

In this report, we present the characterization of three calmodulin clones isolated from a cDNA library that are differentially expressed in bean tissues and during nodule development. Particularly, PvCaM-1 transcript is lowered by the Nod factor. The results presented here suggest that regulation of PvCaM-1 is due to the polar auxin transport inhibition caused by the Nod factor.

\section{RESULTS}

\section{Characterization of calmodulin cDNA clones.}

Three cDNA clones, PvCaM-1, PvCaM-2, and PvCaM-3, containing the complete $\mathrm{CaM}$ coding region were isolated from a nodule library and studied. Nucleotide sequences of the three Phaseolus vulgaris $\mathrm{CaM}$ shows that PvCaM-1 has 858 bp and contains a $5^{\prime}$ untranslated sequence of 93 bp and its $3^{\prime}$ untranslated region is $315 \mathrm{bp}$ long. $\mathrm{PvCaM}-2$ is $852 \mathrm{bp}$ with a 38-bp 5' untranslated region and a 364-bp $3^{\prime}$ untranslated region. PvCaM-3 is 822 bp long with a 19-bp $5^{\prime}$ untranslated region and a $3^{\prime}$ untranslated region of $353 \mathrm{bp}$. All three cDNA

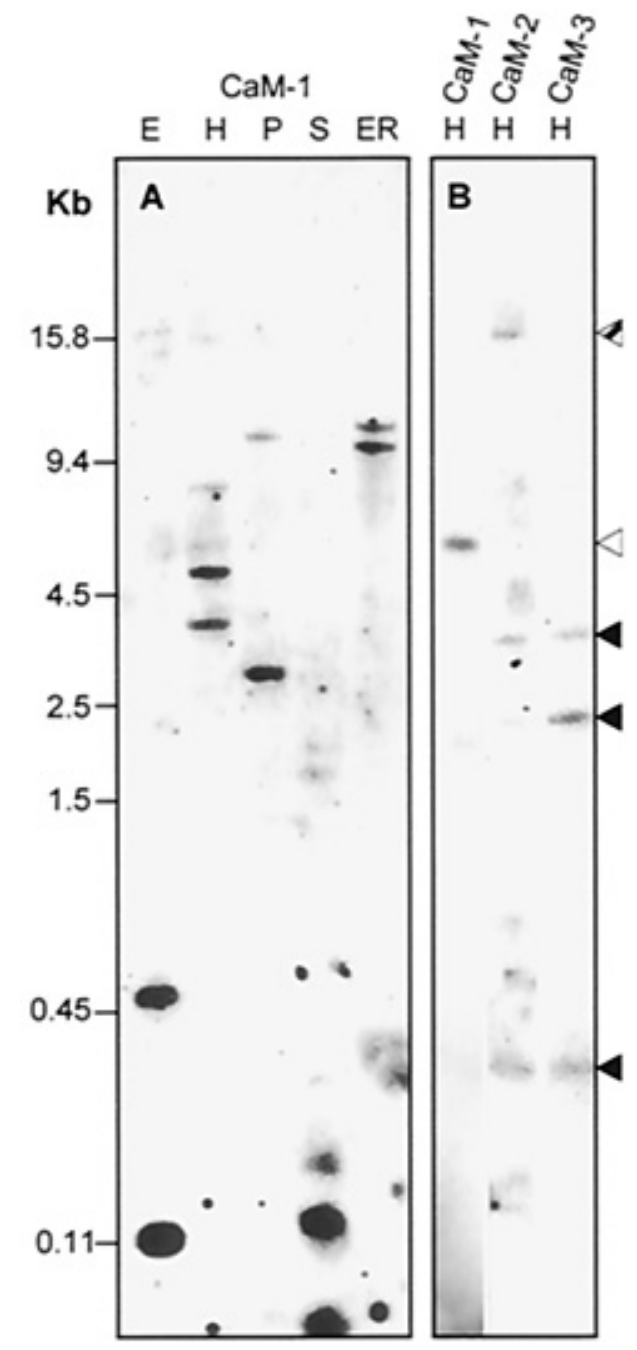

Fig. 2. Genomic Southern analysis of bean calmodulin gene family. Phaseolus vulgaris DNA was digested, size-fractionated on a $0.8 \%$ agarose gel, blotted onto a nylon membrane, and probed with A, PvCam-1 entire coding region or $\mathbf{B}, \mathrm{PvCaM}-1-$, pvCaM-2-, and pvCaM-3-specific probes. Arrowheads indicate the different bands recognized by the PvCaM specific probes. $\mathrm{E}=$ Eco RI, $\mathrm{H}=$ HindIII, $\mathrm{P}=$ Pst $\mathrm{I}, \mathrm{S}=$ Sau3A, and $\mathrm{ER}=$ EcoRV. inserts contain an open reading frame of 444 bp that encodes a 148-aa polypeptide. As with other plant $\mathrm{CaMs}$, the nucleotide sequence of these clones revealed that there is no consensus polyadenylation signal at the $3^{\prime}$ end (Botella and Arteca 1994). The observed differences in nucleotide sequence among these three CaM cDNAs were found dispersed throughout the entire coding region as well as within the untranslated region (data not shown). These results suggest that the three CaM cDNA clones could represent three different CaM genes in $P$. vulgaris. The deduced amino acid sequence of PvCaM-1 is identical to that of alfalfa CaM (Barnett and Long 1990); therefore, we used this clone as a reference to compare the amino acid sequences of PvCaM-2, PvCaM-3, and other calmodulins already reported (Fig. 1A and B). The deduced amino acid sequence of PvCaM-2 shows a nonconservative and unique plant tyrosine (Tyr) substitution at position 118. This substitution of a Tyr for an Asp lies between the third and fourth $\mathrm{Ca}^{2+}$-binding domain. Two Tyr residues have been found in $\mathrm{CaM}$ amino acid sequences reported for different species; however, none of these Tyr residues is at position 118 (Fig. 1B) ( Hyoung et al. 1995; Lagace et al. 1983; Marshak et al. 1984; Poovaiah and Reddy 1993; Vanaman 1980). The deduced amino acid sequence of $\mathrm{PvCaM}-3$ contains a nonconservative alanine (Ala) for serine (Ser) substitution at position 10 with respect to the PvCaM-1 and the alfalfa amino acid sequences (Fig. 1B). The presence of Ala at this position is well represented in CaM polypeptides from vertebrates, invertebrates, and unicellular eukaryotes as well as in potato (Takezawa et al. 1995), barley (Zielinski 1987), and rice (Liu et al. 1993).

\section{CaM genomic DNA organization in bean.}

To obtain more information on the genomic organization of the three CaM clones, $P$. vulgaris DNA was digested with different restriction enzymes and analyzed by Southern blot hybridization using the PvCaM-1 coding region as a common probe and the specific probes for each CaM clone (Fig. 2). When the PvCaM-1 coding region was used as a probe, at least two different-sized restriction fragments were detected in each one of the DNA digests. Minor bands were also observed in EcoRI, HindIII, and SaltI digests but not in the PstI digest (Fig. 2A). When specific probes were used to hybridize HindIII-digested DNA, the PvCaM-1-specific probe showed a single restriction fragment $(5.3 \mathrm{~kb})$ (Fig. $2 \mathrm{~B}$, white arrowhead) that was not detected with either PvCaM-2- or PvCaM-3-specific probes. When HindIII-digested DNA was hybridized with PvCaM-2- or with PvCaM-3-specific probes, three common fragments of $0.43,2.3$, and $3.5 \mathrm{~kb}$ were detected (Fig. 2B, black arrowheads). Another 15.8-kb fragment was detected only when a PvCaM-2-specific probe was used (Fig. 2B, dash arrowhead). These results indicate that the PvCaM-1 clone represents a single member of a $\mathrm{CaM}$ gene family and suggest that PvCaM-2 and PvCaM-3 represent either two closely related genes or two alleles.

Further genomic characterization of these $\mathrm{CaM}$ clones was carried out by amplification of the intron regions from total DNA, using specific primers. A 1.4-kbp fragment was amplified for PvCaM-1 and a 2.0-kbp fragment was amplified for PvCaM-2 and PvCaM-3. Considering the corresponding position of the specific primers in its cDNA clones, the data obtained indicate that calmodulin gene $P v C a M-1$ contains a 940bp intron and that $P v C a M-2$ and $P v C a M-3$ introns are 1,212 and 1,375 bp long, respectively (data not shown).

Similar results have been published for rice, where $\mathrm{CaM}$ is also coded by a multigene family. Rice CaM-1 and CaM-2 genes contain a single 1,400- and a 300-bp-long intron, respectively (Poovaiah and Reddy 1993). 
Calmodulin protein in bean tissues.

$\mathrm{CaM}$ protein levels were determined in the stem, root, and nodule at 12,15 , and 25 days after inoculation. As shown in Figure 3, calmodulin protein is abundant in nodules at 15 and 25 days but is very sparse in stems, roots, and 12-day nodules. Additionally, in these later three tissues, CaM protein electrophoretic migration is slower than that for 15- and 25day nodules. To explain this difference in electrophoretic mobility, purified CaM from spinach (S-CaM) and from PvCaM-1, PvCaM-2, and PvCaM-3 expressed in Escherichia coli were incubated in the presence of and in the absence of $\mathrm{Ca}^{2+}$ (eliminated with EGTA). Our results indicate that the lighter protein band corresponds to $\mathrm{Ca}^{2+}$-bound $\mathrm{CaM}$ and that the heavier band corresponds to $\mathrm{Ca}^{2+}$-free $\mathrm{CaM}$ (Fig. 3). These results indicate, first, that the amount of $\mathrm{CaM}$ protein is higher in mature nodules than in young nodules and, second that, considering the low amount of $\mathrm{CaM}$ protein in other tissues, CaM could be a nodule-enhanced protein. Previous works indicated that the amount of $\mathrm{CaM}$ protein is higher in nodules than in roots (Jablonsky et al. 1991). Two protein bands can be detected in stems and roots (Fig. 3), suggesting that bean calmodulin may be polyubiquitinated in these tissues, as has been reported earlier (Ziengenhagen and Jenissen 1990). Protein blotting was carried out with anti$\mathrm{CaM}$ monoclonal antibodies; therefore, a nonspecific immunoreactivity is unlikely.

\section{CaM expression in bean tissues.}

To determine whether these three $P$. vulgaris CaM clones are differentially expressed in plant tissues and during nodule development, RNA isolated from the cotyledons, stem, leaves, roots, root apex, and nodules was hybridized with specific $P$. vulgaris $\mathrm{CaM}$ probes. A single band of approximately $1.2 \mathrm{kbp}$ was detected on autoradiograms, corresponding to the predicted size of CaM mRNA. PvCaM-1 was expressed in young roots, root apex, and cotyledons but was not detected in either stems or leaves (Fig. 4A and B). During nodule development, $P v C a M-1$ transcripts reached maximal expression at days 15 and 18 and declined by day 21 (Fig. 4C). PvCaM-2 and $P v C a M-3$ expression pattern was the same in all tissues tested; however, $P v C a M-2$ transcripts seemed to be the most abundant. Both transcripts were expressed in almost all tissues tested except in mature stems (Fig. 4). $P v C a M-2$ and $P v C a M-3$ transcript levels were higher in root apex than in other tissues (Fig. 4A). In nodules, both transcripts declined gradually from day 13 to 21 after inoculation (Fig. 4C). $P v C a M-2$ and $P v C a M-3$ expression occurred early, during nodule development, because their transcript levels were high at 11 days after inoculation, similar to that seen with early nodulin ENod40. However, ENod40 mRNA levels did not decline, remaining almost constant until day 18 after inoculation (Fig. 4D).
Effect of Nod factor on the expression of PvCaM clones.

As mentioned above, Nod factor promotes nodule formation stimulating cell division on root cortex. To determine whether nodule CaM participates in the initial signaling of nodule formation, CaM transcript levels were examined in roots exposed to Nod factor. As shown in Figure 5, expression of PvCaM-1 in roots was clearly inhibited by Nod factor after 48 and $96 \mathrm{hr}$, and the expression of $P v C a M-2$ and $P v C a M-3$ also was reduced, but to a much lesser extent. Conversely, ENod40 expression was highly increased by the presence of Nod factor (mainly after $48 \mathrm{hr}$ ) (Fig. 5). These results suggest that PvCaM-1 does not participate in the initial events signaled by the Nod factor. A common feature between the PvCaM clones and ENod40 is that their expression increased significantly from nodule primordia to nodulelike structure (Fig. 5A and B). However, ENod40 expression was higher than that of PvCaM clones in nodule primordia. These data suggest a role of these genes in nodule development.

\section{Polar auxin transport and PvCaM-1 expression.}

Experiments were done to explain the Nod factor inhibition of $P v C a M-1$ expression. Taking into account that Nod factor reduces auxin transport capacity (Boot et al. 1999; Hirsh et al. 1989; Mathesius et al. 1998) and that an increase in auxin levels increases CaM expression (Yang and Poovaiah 2000), bean roots were cotreated with the Nod factor and indole acetic acid and with a polar auxin transport inhibitor (TIBA) alone or in the presence of indole-3-acetic acid (IAA). Our results demonstrated that the Nod factor, as well as TIBA, inhibits CaM-1 expression (Fig. 6, lanes 2 and 4). This inhibition was prevented when IAA is present (Fig. 6, lanes 3 and 5). These results suggest that the regulation of CaM-1 by the Nod factor is mediated by auxins.

\section{DISCUSSION}

\section{Calmodulin cDNA clones}

and CaM genomic organization in beans.

Three complete CaM clones from a cDNA library derived from 15-day-old root nodules were characterized. The nucleotide sequence comparison at the coding region shows 62 to $74 \%$ homology and, at the $3^{\prime}$ untranslated region, an identity of 69 to $77 \%$. The differences in nucleotide sequence among the three CaM-cDNAs are distributed throughout the coding regions as well as in the $5^{\prime}$ and $3^{\prime}$ untranslated regions of the clones (data not shown).

Southern blot analysis (Fig. 2) suggests that nodule CaM cDNAs are derived from different genomic DNA sequences and that calmodulin is encoded by a gene family in beans. These data are in agreement with the finding that $\mathrm{CaM}$ is encoded by a gene family in Arabidopsis spp. (Gawienowski et al. 1993), po-

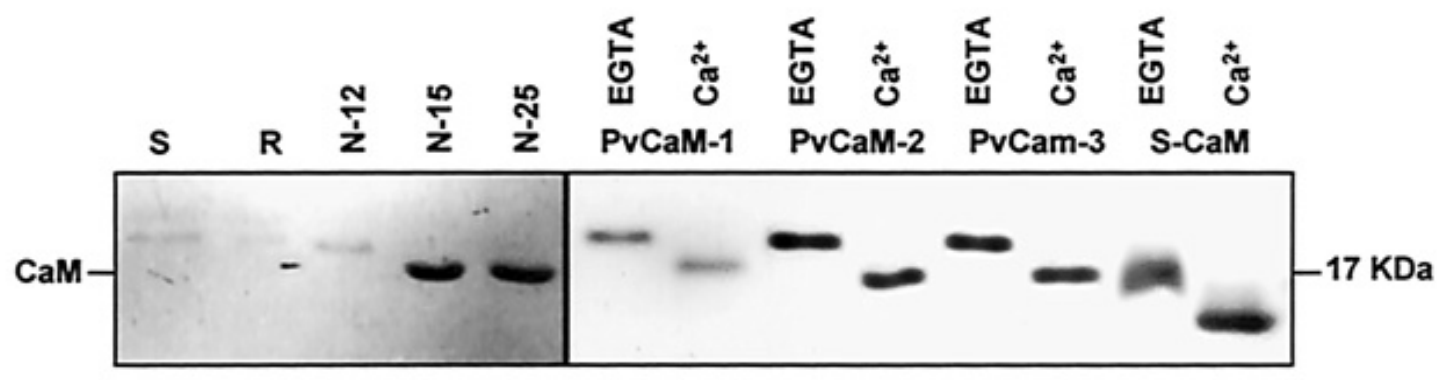

Fig. 3. A, Immunoblot detection of calmodulin in different plant tissues. $\mathrm{R}=$ root; $\mathrm{S}=$ stem; N-12, N-15, and N-25 = nodules 12,15 , and 25 days postinoculation. B, Analysis of $\mathrm{Ca}^{2+}$-mediated electrophoretic mobility shifts of purified proteins from PvCaM-1, pvCaM-2, and pvCaM-3 expressed in Escherichia coli. Pure spinach calmodulin (S-CaM) was used as control. 
tato (Takezawa et al. 1995), and Vigna radiata (Botella and Arteca 1994). Hybridization analysis of HindIII-digested DNA using $\mathrm{PvCaM}$-specific probes suggests that $\mathrm{PvCaM}-1$ is a calmodulin gene well distinct from $P v C a M-2$ and $P v C a M-3$, because both PvCaM-2- and PvCaM-3-specific probes detected three common fragments that were not detected with PvCaM-1 and because the PvCaM-1-specific probe detected a single fragment that is not detected with either a PvCaM-2 or a PvCaM-3 probe. A PvCaM-2 probe detected a $15.8-\mathrm{kb}$ fragment that is not detected with a PvCaM-3 probe; therefore, these two clones could represent two closely related genes. Moreover, genomic characterization shows that the $P v C a M-1$ gene has an intron smaller than that observed for $P v C a M-2$ and $P v C a M-3$ (data not shown). Preliminary nucleotide sequences of $P v C a M-2$ and $P v C a M-3$ introns indicated that they are different (data not shown). However, the expression patterns of $P v C a M-2$ and $P v C a M-3$ are almost identical in different tissues and during nodule development; therefore, we believe that more studies are needed to ascertain whether $P v C a M-2$ and $P v C a M-3$ represent two different genes or are alleles.

\section{Calmodulin amino acid sequences.}

Regarding the Ala/Ser substitution at position 10, the PvCaM-3 clone seems to be functionally conservative
(Creighton 1993). However, Tyr at position 118 in the PvCaM2 clone is a unique substitution that has not been described in plant CaM. This change lies between the third and fourth $\mathrm{Ca}^{2+}$ binding domains and may have important physiological effects. After $\mathrm{Ca}^{2+}$ binding, a transition between two stable conformational states of CaM occurs, affecting the environment around Tyr 138 and trimethyllysine at position 115. This change increases the $\alpha$-helix content of the protein. These two residues are conserved in plants calmodulin (Roberts and Harmon 1992); therefore, the presence of Tyr 118 close to trimethyllysine 115 and Tyr 138 could be involved in these conformational changes in PvCaM-2. Also, Tyr 118 could represent a putative phosphorylation site. The presence of two acidic residues (glutamic acid) at position $\mathrm{P}+1$ and $\mathrm{P}+2$ and a hydrophobic residue (valine) at position $\mathrm{P}+3$ of Tyr 118 in clone PvCaM-2 (Fig. 1) represents two of the most important features of cytosolic protein tyrosine kinase phosphorylation sites (Zhou and Lewis 1995). More studies need to be done in order to understand the physiological meaning of these amino acid substitutions.

\section{Calmodulin expression in bean tissues.}

Northern analysis carried out using PvCaM-specific probes (Fig. 4A and B) showed that in all tissue tested, PvCaM-2 and

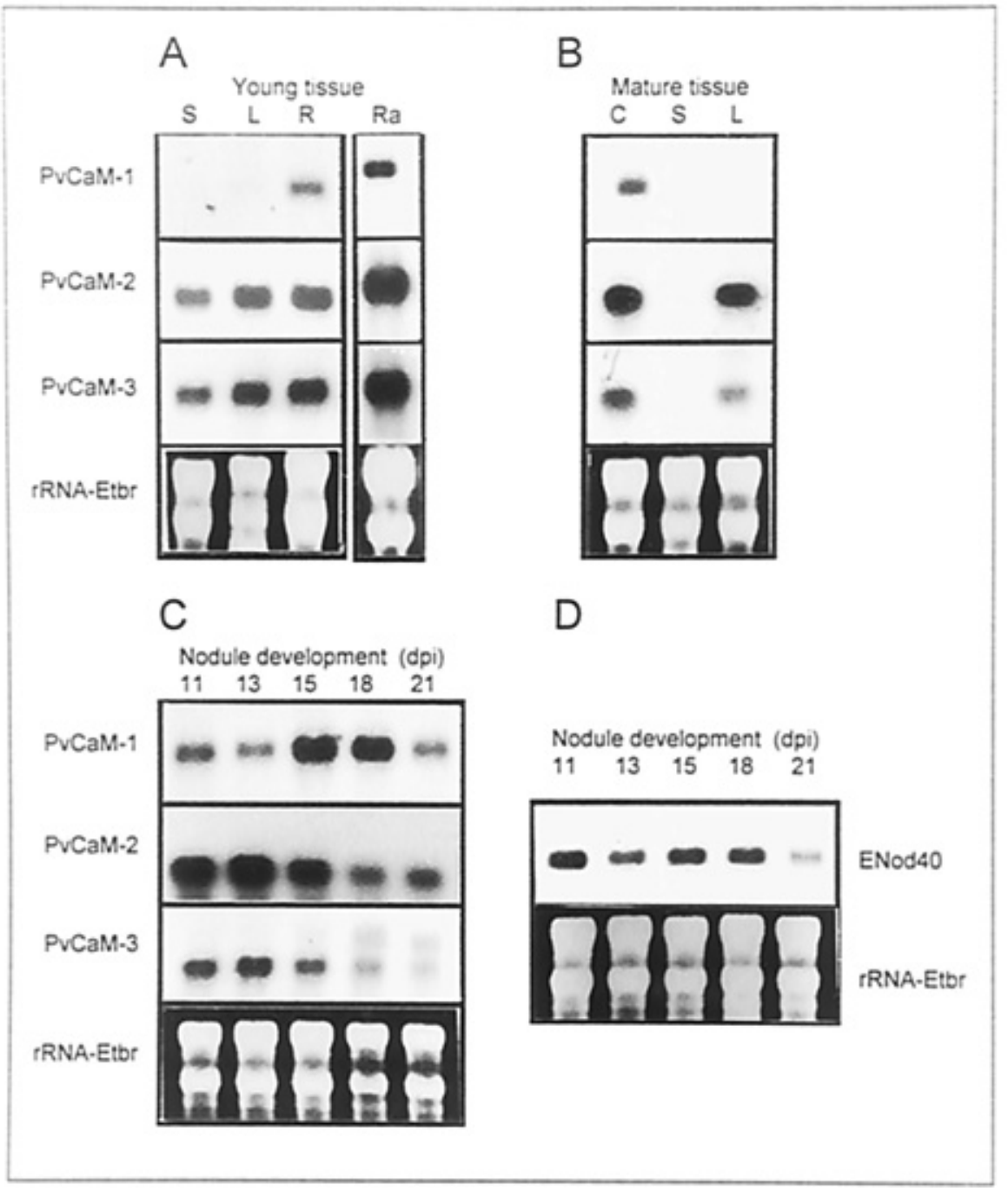

Fig. 4. Calmodulin and Enod 40 mRNA levels in different tissues of Phaseolus vulgaris. Total RNA was separated in formaldehyde/agarose gels, blotted onto a nylon membrane, and hybridized with ${ }^{32} \mathrm{P}$-labeled pvCaM-1-, pvCaM-2-, and pvCaM-3-specific probes. Transcript levels of CaM in A, young tissues: stems (S), leaves (L), roots (R), and root apex (Ra); B, mature tissues: cotyledons (C), stems (S), and leaves (L); and $\mathbf{C}$ and $\mathbf{D}$, nodules from 11 to 21 days postinoculation (10 to $15 \mu \mathrm{g}$ loaded per lane in independent experiments). 
$P v C a M-3$ display a very similar expression pattern that is different from $P v C a M-1$, supporting the idea that $P v C a M-2$ and $P v C a M-3$ could be alleles and that $P v C a M-1$ represents a different gene. In general, the main expression of these three $\mathrm{PvCaM}$ clones was detected in young tissues and meristems. This expression pattern is similar to that reported for other plant CaM genes (Allan and Trewavas 1985; Dauwalder et al. 1986; Ling and Assman 1992; Yang et al. 1998). It is important to note that, as in other plant species, these three PvCaM clones were found to display a very high expression in the root apex, which is considered a perception organ (Lu and Feldman 1997; Stinemetz et al. 1987). PvCaM-1 expression was not detected in stem and leaves, as reported for the wheat calmodulin SF-1 clone (Yang et al. 1998).

\section{Calmodulin expression during nodule development.}

In bean nodules, all three CaM clones were expressed at all the times examined. The higher levels of $P v C a M-2$ and $P v C a M$ 3 transcripts were detected starting on day 11 and of $P v C a M-1$ at days 15 and 18 after inoculation. The higher expression of $P v C a M-1$ at this time could suggest a metabolic role of this $\mathrm{CaM}$, because increased nitrogenase activity, carbon metabolism, and ammonia assimilation and transport occurs during this period. The presence of noduline 26 (Weaver et al. 1991) and glutamic acid decarboxylase (GAD), which are $\mathrm{Ca}^{2+}$ (calmodulin)-regulated enzymes, and the accumulation of $\gamma$ Amino-n-butyric acid in nodules (Ling et al. 1994; Satnarayan and Nair 1990) supports this idea. However, our results show a discrepancy between the amount of CaM protein and the transcript levels during nodule development. Protein concentration increased from day 12 to day 21 and up to day 25 (Fig. 3), while all PvCaM transcripts decreased by day 21 after inoculation (Fig. 4). This $\mathrm{CaM}$ protein accumulation in mature nodules could suggest that the main role of $\mathrm{CaM}$ is related to nodule function instead of nodule development. However, specific anti- bodies raised against each one of the three $\mathrm{CaM}$ isoforms need to be obtained in order to define if this $\mathrm{CaM}$ protein accumulation is due to all $\mathrm{CaM}$ isoforms or to a specific one, allowing us to further study $\mathrm{CaM}$ function during symbiosis.

\section{Calmodulin expression in the presence of Nod factor.}

$\mathrm{PvCaM}$ transcripts also were detected in nodule primordia and, in higher levels, in the nodulelike structure induced by Nod factor. Interestingly, CaM expression in nodule primordia is very low compared with the CaM transcript levels detected in root apex (Fig. 5), suggesting that $P v C a M$ genes are differentially expressed in these two types of meristematic tissues. A clear reduction in the expression of $P v C a M-1$ and, to a lesser extent, of $P v C a M-2$ and $P v C a M-3$ was promoted by the Nod factor (Fig. 5). As is shown in Figure 6, reduction of PvCaM-1 transcript induced by the Nod factor also is observed when roots are treated with TIBA but is prevented when either Nod factor- or TIBA-treated roots are in the presence of IAA. With these results, we can conclude that Nod factor negative regulation of $P v C a M-1$ gene expression is mediated by auxin. Also, our results suggest that CaM does not participate in the initial events of the symbiotic process but does participate in early events of nodule formation. More studies need to be done in order to understand if the early Nod factor negative regulation of CaM-1 gene expression is a key factor that allows nodule development.

\section{MATERIALS AND METHODS}

Plant material.

P. vulgaris L. (cv. Negro Jamapa) seeds were surface sterilized and germinated for 2 days before inoculation and were sown in pots with vermiculite. Seedlings were inoculated with Rhizobium leguminosarum bv. phaseoli strain CNPAF-512 (Hungria et al. 1991). Plants were grown and maintained under

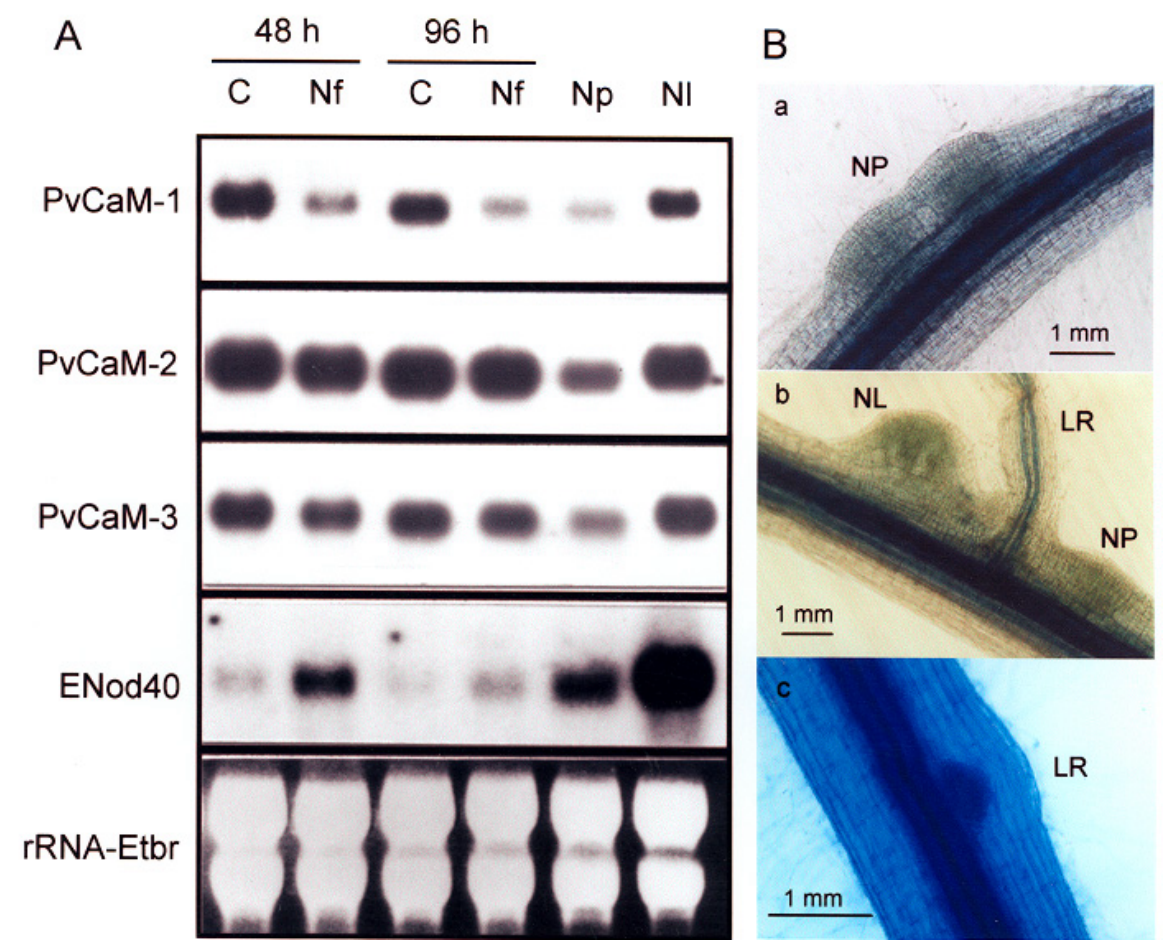

Fig. 5. Effect of Nod factors on CaM and Enod40 mRNA levels. A, Total mRNA from roots grown in the absence (C) and presence (Nf) of Rhizobium etlipurified Nod factor and from nodule primordia ( $\mathrm{Np}$ ) and nodulelike structures (Nl) induced by the Nod factor was hybridized with ${ }^{32} \mathrm{P}-1 \mathrm{labeled} \mathrm{PvCaM}-1-$, pvCaM-2-, and pvCaM-3-specific probes. B, Nodule primordia (a) and nodulelike (b) structures were completely absent in the control roots (c). LR = lateral root; rRNA-Etbr = ethidium bromide-stained rRNA before transfer to nylon membrane, indicating the relative amount of RNA analyzed. 
greenhouse conditions as previously described (Lara et al. 1984). Nodules were harvested from day 11 after Rhizobium inoculation onward and were immediately frozen in liquid nitrogen.

\section{Isolation of $\boldsymbol{P}$. vulgaris CaM-cDNA clones.}

Using a $\lambda$ gt-22a cDNA library derived from $P$. vulgaris nodules (provided by Dr. Carroll Vance, University of Minnesota, St. Paul), the CaM coding region probe was generated by polymerase chain reaction (PCR). Primers were designed from $\mathrm{CaM}$ consensus sequence in different plant species. The sequences are 5'-dATGGCCGATCAGCTCACCGACGATC AGATC- $3^{\prime}$ and $3^{\prime}$-dCAAGCAGTTTCAGTACTACCGGTTCACTC-5'. PCR protocol was performed as described by Friedman and associates (1990). Samples were heated to $94^{\circ} \mathrm{C}$, kept for $4 \mathrm{~min}$ at this temperature, and then subjected to $35 \mathrm{cy}$ cles of the following sequence: $1 \mathrm{~min}$ at $94^{\circ} \mathrm{C}, 1.5 \mathrm{~min}$ at $55^{\circ} \mathrm{C}$, and $2 \mathrm{~min}$ at $72^{\circ} \mathrm{C}$. Subsequently, they were subjected for $5.0 \mathrm{~min}$ to $72^{\circ} \mathrm{C}$ and stored at $4^{\circ} \mathrm{C}$ until use. Amplified product was separated by agarose gel electrophoresis, purified (Geneclean II Kit; BIO 101, Inc., Vista, CA, U.S.A.), and used as a probe for the $\lambda$ Zap cDNA library screening.

A $\lambda$ Zap cDNA library derived from 15 -day-old bean nodule mRNA was used to isolate bean calmodulin clones. Plaque hybridization was performed at $42^{\circ} \mathrm{C}$. Filters were washed in $2 \times$ SSC ( $1 \times \mathrm{SSC}$ is $0.15 \mathrm{M} \mathrm{NaCl}$ plus $0.015 \mathrm{M}$ sodium citrate), $0.1 \%$ sodium dodecyl sulfate (SDS) and in $1 \times$ SSC, $0.1 \%$ SDS at $65^{\circ} \mathrm{C}$. The filters were rinsed and exposed to a Kodak X-ray film. Three positive hybridizing clones (PvCaM-1, PvCaM-2, and $\mathrm{PvCaM}-3$ ) were purified by three rounds of plaque hybridization.

\section{Characterization of $\boldsymbol{P}$. vulgaris CaM-cDNA clones.}

cDNA inserts from positively hybridizing phage were excised in the pbluescript $\mathrm{SK}^{+}$plasmid (Stratagene, La Jolla, CA, U.S.A.) and transformed into "SOLR" strain (Stratagene). The pbluescript $\mathrm{SK}^{+}$recombinant plasmid was purified and digested with PstI and XhoI restriction enzymes. Inserts were subjected to electrophoresis in $1 \%$ agarose gels, blotted to Hybond- $\mathrm{N}^{+}$filters (Amersham Pharmacia Biotech, Buckinghamshire, U.K.), and hybridized with a ${ }^{32} \mathrm{P}$-labeled CaM coding region probe. The filter was washed progressively with: $2 \times$ SSC, $0.1 \%$ SDS; $1 \times$ SSC, $0.1 \%$ SDS; and $0.1 \times$ SSC, $0.1 \%$ SDS. All washes were carried out at $65^{\circ} \mathrm{C}$. The filter was exposed to Kodak X-ray film at $-70^{\circ} \mathrm{C}$.

\section{Sequence analysis.}

DNA sequencing was performed by the dideoxy chain termination method using Sequenase (ver. 2.0 DNA sequencing kit; Amersham Pharmacia Biotech) and $\left({ }^{35} \mathrm{~S}\right)$-ATP with double stranded plasmid DNA template. Both strands were sequenced using $\mathrm{T}_{7}$ and $\mathrm{T}_{3}$ universal primers.

\section{Genomic southern analysis.}

Total DNA was isolated from $P$. vulgaris leaves, using the cetyltrimethylammonium bromide procedure as described by Murray and Thompson (1980). Final yield was $250 \mu \mathrm{g}$ of total DNA per $g$ of tissue. Total DNA $(10 \mu \mathrm{g})$ was electrophoresed, digested with different restriction enzymes, blotted onto a nylon membrane, and then, hybridized using the PvCaM-1 coding region as a common probe and against specific probes for each of the three PvCaM clones. To obtain clone-specific probes, cDNAs oligonucleotide primers were synthesized, enabling the recovery of the $3^{\prime}$ untranslated regions by PCR. A common sense primer anchored in the carboxyl terminus of the coding region was used in conjunction with clone-specific antisense primers for each one of the CaM clones. PCR fragments are 258, 369, and 205 bp long for PvCaM-1, PvCaM-2, and PvCaM-3, respectively. These PCR-generated fragments do not cross-hybridize on DNA blots at high astringency (data not shown). Genomic hybridization was carried out at $50^{\circ} \mathrm{C}$ for $16 \mathrm{hr}$ in a solution containing $0.3 \mathrm{M} \mathrm{NaH}-2 \mathrm{PO}_{4}, \mathrm{pH} 7.2,10 \mathrm{mM}$ EDTA, and 7\% (wt/vol) SDS with ${ }^{32} \mathrm{P}$-labeled PvCaM-1 and PvCaM-1-, PvCaM-2-, and PvCaM-3-specific probes. The membranes were washed at $55^{\circ} \mathrm{C}$ with $2 \times \mathrm{SSC}, 0.1 \%$ SDS, and exposed to Kodak film at $-70^{\circ} \mathrm{C}$.

\section{CaM introns analysis.}

Total DNA (50 ng) was used to perform a genomic PCR analysis using the $\mathrm{CaM}$ primers described above. PCR program was as follows: denaturing step at $94^{\circ} \mathrm{C}$ for $1 \mathrm{~min}$, annealing at $55^{\circ} \mathrm{C}$ for $1.5 \mathrm{~min}$, and extension at $72^{\circ} \mathrm{C}$ for 2.0 $\mathrm{min}$, with a final extension segment for $5.0 \mathrm{~min}$ at $72^{\circ} \mathrm{C}$. The reaction was carried out for a total of 35 cycles. Following chloroform extraction, the reaction products were fractionated by electrophoresis in $1 \%(\mathrm{wt} / \mathrm{vol})$ agarose gel.

\section{Western blot analysis of $\boldsymbol{P}$. vulgaris calmodulin.}

Total protein of nodule and other plant tissues was extracted with three volumes (wt/vol) of extraction buffer $(50 \mathrm{mM}$ HEPES, $5 \mathrm{mM}$ dithiothreitol, $1 \mathrm{mM}$ phenylmethylsulfonyl flouride, $20 \%$ glycerol, $5 \%$ ethylenglycol, $\mathrm{pH} 7.8$ ). The homogenate was then centrifuged $(20 \mathrm{~min}, 20,000 \times \mathrm{g})$ and proteins in the supernatant were solubilized in Laemmli buffer (Laemmli 1970). Samples of $10 \mu \mathrm{g}$ of protein were analyzed in $15 \%$ SDS-polyacrylamide gel electrophoresis (PAGE) gels.

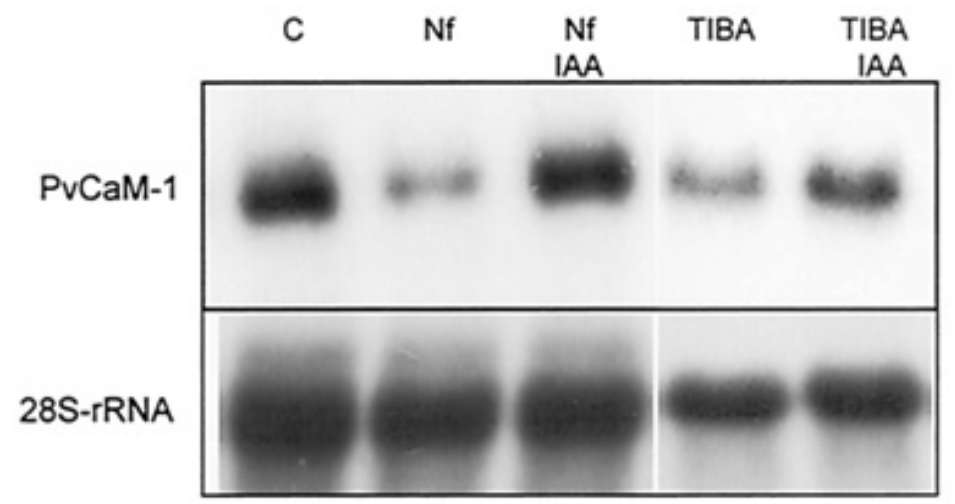

Fig. 6. Northern blot analysis showing the effect of Nod factor or 2,3,5-triiodobenzoic acid (TIBA), alone or in combination with indole-3-acetic acid (IAA), on the expression of PvCaM-1 gene. Total mRNA from root segments was isolated at $48 \mathrm{hr}$ after each treatment. A ${ }^{32} \mathrm{P}-1 \mathrm{abeled} \mathrm{PvCaM}-1 \mathrm{clone}-\mathrm{specific}$ probe was used for hybridization. Lane $\mathrm{C}$ shows mRNA from roots grown in the absence of the Nod factor. Nf and TIBA indicate the presence of the Nod factor or TIBA, with and without IAA. Hybridization against a 28S-rRNA probe was used as an RNA loading control. 
Proteins were transferred to nitrocellulose filter (Amersham) and Western blots were performed using commercial rabbit anti-CaM monoclonal antibodies raised against Dictyostelium discoideum (Sigma C-7055, Sigma-Aldrich Co., Milwaukee, WI, U.S.A.) as the primary antibody. A peroxidase-linked mouse antirabbit antibody was used as the secondary antibody and the peroxidase color reaction was developed following Sigma's instruction.

\section{SDS-PAGE mobility shift assay of purified bean CaM.}

The coding region of the $P$. vulgaris $\mathrm{CaM}$ cDNA clones were subcloned into the expression vector PQE-30 (QIAexpress, QIAGEN, Hilden, Germany) and transformed into E. coli cells (M-15). Cultures were grown at $37^{\circ} \mathrm{C}$ until the optical density at $600 \mathrm{~nm}$ reached 0.7 before addition of IPTG to a final concentration of $1 \mathrm{mM}$. After $3.0 \mathrm{hr}$ in the induction medium, in vitro-expressed $\mathrm{CaM}$ was purified by affinity chromatography using Ni-NTA resin (QIAexpress) following the manufacturer's instructions. The eluted protein from the resin was resuspended in $50 \mathrm{mM}$ Tris- $\mathrm{HCl}, \mathrm{pH} \mathrm{7.5}$, buffer and purified $\mathrm{CaM}$ was analyzed by $15 \%$ SDS-PAGE in the presence of either $2 \mathrm{mM} \mathrm{CaCl}_{-2}$ or $2 \mathrm{mM}$ EGTA.

\section{Nod factor assays.}

Two-day-old seedlings were placed in assay tubes containing Fahraeus buffer (Fahraeus 1957). After $2.0 \mathrm{hr}$, roots were treated with purified $R$. etli Nod factor (Cárdenas et al. 1995, 1998) or TIBA, alone or in combination with IAA, all diluted to a final concentration of $1 \times 10^{-6} \mathrm{M}$. After eliminating the root apex (3 mm), 2-cm-long root segments were harvested at 48 and $96 \mathrm{hr}$. Nodule primordia and nodulelike structures were dissected independently. All tissues were stored at $-70^{\circ} \mathrm{C}$ until they were analyzed.

\section{RNA isolation and northern hybridizations.}

Total RNA was isolated from $250 \mathrm{mg}$ of cotyledons, roots, stems, leaves, nodule primordia, nodulelike structures, and nodules tissues at different times, as indicated, using a guanidinium thyocianate procedure (RNA aid plus kit, Bio. 101, Inc.) electrophoresed on formaldehyde-agarose gels and blotted onto Hybond- $\mathrm{N}^{+}$filters according to the manufacturer's instructions. Hybridizations were carried out at $50^{\circ} \mathrm{C}$ for $16 \mathrm{hr}$ in $0.3 \mathrm{M}$ $\mathrm{NaH}_{-2} \mathrm{PO}_{4}, \mathrm{pH} 7.2,10 \mathrm{mM}$ EDTA, and 7\% (wt/vol) SDS with ${ }^{32} \mathrm{P}-$ labeled PvCaM-1-, PvCaM-2-, and PvCaM-3-specific probes. 28S-rRNA probe was used as an RNA loading control (Colmenero et al. 1997) All washes were carried out at $65^{\circ} \mathrm{C}$.

\section{ACKNOWLEDGMENTS}

We thank M. C. Lourdes Blanco and C. P. Vance for providing the $\lambda$ Zap and $\lambda$ gt-22a libraries; M. Matvienko for the PsEnod40 clone; A. Sánchez and J.-L. Zitlalpopocatl for their technical support in the greenhouse; P. Gaytan and E. López for oligonucleotide synthesis; and R. Hernández for technical assistance in DNA sequencing. This project was supported partially by U.N.A.M. Dirección General de Asuntos del Personal Académico grant number IN-216696; Consejo Nacional de Ciencia y Tecnología (CONACyT) grant G31751-B; and fellowships for A. Camas from CONACyT and from Programa de Apoyo a las Divisiones de Estudios de Posgrado (PADEP), UACPyP-CCH, U.N.A.M.

\section{LITERATURE CITED}

Allan, E., and Trewavas, A. J. 1985. Quantitative changes in calmodulin and NAD kinase during early cell development in root apex of Pisum sativum. Planta 165:493-501.

Barnett, M. J., and Long, S. R. 1990. Nucleotide sequence of an alfalfa calmodulin cDNA. Nucleic Acids Res. 18:3395.

Baum, G., Lev-Yadun, S., Fridmann, Y., Arazi, T., Katsnelson, H. Z. M. and Fromm, H. 1996. Calmodulin binding to glutamate decarboxylase is required for regulation of glutamate and GABA metabolism and normal development in plants. EMBO (Eur. Mol. Biol. Organ.) J. 29882996.

Boot, K. J. M., van Brussels, A. A. N., Tak, T., Spaink, H. P., and Kijne, J. W. 1999. Lipochitin oligosaccharides from Rhizobium leguminosarum bv. viciae reduce auxin transport capacity in Vicia sativa subsp. nigra roots. Mol. Plant-Microbe Interact. 12:839-844.

Botella, J. R., and Arteca, R. N. 1994. Differential expression of two calmodulin genes in response to physical and chemical stimuli. Plant Mol. Biol. 24:757-766.

Braam, J., and Davis, R. W. 1990. Rain-, wind-, and touch-induced expression of calmodulin and calmodulin related genes in Arabidopsis. Cell 60:357-364.

Cárdenas, L., Vidali, L., Domínguez, J., Pérez, H., Sánchez., F., Hepler, H., and Quinto, Carmen. 1998. Rearrangement of actin microfilaments in plant root hairs responding to Rhizobium etli nodulation signals. Plant Physiol. 116:871-877.

Chen, Y., Baum, G., and Fromm, H. 1994. The 58-kilodalton calmodulinbinding glutamate decarboxylase is an ubiquitous protein in Petunia organs and its expression is developmentally regulated. Plant Physiol. 106:1381-1387.

Colmenero-Flores, J. M., Campos F., Garciarrubio, A., and Covarrubias, A. A. 1997. Characterization of Phaseolus vulgaris cDNA clones responsive to water deficit: Identification of a novel late embryogenesis abundant-like protein. Plant Mol. Biol. 35:393-405.

Creighton, T. E. 1993. Pages 105-138 in: Protein: Structures and Molecular Properties. Freeman and Co., New York.

Dauwalder, M., Roux, S. J., and Hardison, L. 1986. Distribution of calmodulin in pea seedlings: Immunocytochemical localization in plumules and root apices. Planta 168:461-470.

Dénarié, J., Debellé, F., and Promé, J. C. 1996. Rhizobium lipochitooligosaccharide nodulation factors: Signaling molecules mediating recognition and morphogenesis. Annu. Rev. Biochem. 65:503-535.

Durso, N. A., and Cyr, R. J. 1994. A calmodulin-sensitive interaction between microtubules and a higher plant homolog of elongation factor$1 \alpha$. Plant Cell 6:893-905.

Erhardt, D. W. Atkinson, E. M., Long, S. R. 1992. Depolarization of alfalfa root hair membrane potential by Rhizobium meliloti Nod factors Science 256:998-1000.

Erhardt, D. W., Wais, R., and Long, S. R. 1996. Calcium spiking in plant root hairs responding to Rhizobium nodulation signals. Cell 85:673681.

Fahraeus, G. 1957. The infection of clover root hairs by nodule bacteria studied by a simple glass slide technique. J. Gen. Microbiol. 16:374-381.

Felle, H. H., Kondorosi, E., Kondorosi, A., and Schultze, M. 1998. The role of ion fluxes in Nod factor signaling in Medicago sativa. Plant J. 13:455-463.

Friedman, K. D., Rosen, N. L., Newman, P. J., and Montgomery, R. R. 1990. Screening of $\lambda$ gt11 libraries. Pages 253-257 in: PCR Protocols: A Guide to Methods and Applications. M. Innis, ed. Academic Press, San Diego, CA, U.S.A.

Gawienowski, M. C., Szymanski, D., Perera, I. Y., and Zielinski, R. E. 1993. Calmodulin isoforms in Arabidopsis encoded by multiple divergent mRNAs. Plant Mol. Biol. 22:215-225.

Haiech, J., Kilhoeffer, M. C., Lukas T. J., Craig T. A., Roberts, D. W., and Watterson, D. M. 1991. Restoration of the calcium binding activity of mutant calmodulins toward normal by the presence of a calmodulin binding structure. J. Biol. Chem. 266:3427-3431.

Harper, J. F., Hong, B., Hwang, I., Guo, H. Q., Stoddard, R., Huang, J. F., Palmgren, M. G., and Sze, H. 1998. A novel calmodulin-regulated $\mathrm{Ca}^{2+}$-ATPase (ACA-2) from Arabidopsis with an N-terminal autoinhibitory domain. J. Biol. Chem. 273:1099-1106.

Hirsch, A. M., Bhuvaneswari, T. V., Torrey, J. G., and Bisseling, T. 1989. Early nodulin genes are induced in alfalfa root outgrowths elicited by auxin transport inhibitors. Proc. Natl. Acad. Sci. U.S.A. 86.1-244-1248.

Hirsch, A. M., and Fang, Y. 1994. Plant hormone and nodulation: What's the connection? Plant Mol. Biol. 26:5-9.

Hirsch, A. M., Fang, Y., Asad, S., and Kapulnik, Y. 1997. The role of phytohormones in plant-microbe symbiosis. Plant Soil 194:171-184.

Hungria, M., Barradas, A. A., and Wallgrove, R. M. 1991. Nitrogen fixation, assimilation, and transport during the initial growth stage of Phaseolus vulgaris L. J. Exp. Bot. 42:839-844.

Hyoung, L. S., Cheol, K. J., Soon, L. M., Do H. W., Young, S. H., Won, Y. H., Chan, H. J., Yeol, L. S., Dong, B. J., Hwang, I., and Je, C. M. 1995. Identification of a novel divergent calmodulin isoform from soybean which has differential ability to activate calmodulin-dependent enzymes. J. Biol. Chem. 270:21806-21812.

Ikura, M., Clore, G. M., Gronenborn, A. M., Zhu, G., Klee, C. B., and Box, A. 199-2. Solution structure of a calmodulin-target peptide complex by multidimensional NMA. Science 256:632-638. 
Jablonsky, P., Grolig, F., Perkin, J. L., and Williamson, R. E. 1991. Properties of monoclonal antibodies to plant calmodulin. Plant Sci. 76:175184.

Laemmli, U. K. 1970. Cleavage of structural proteins during the assembly of the head of bacteriophage $\mathrm{T}_{4}$. Nature 227:680-685.

Lagace, L., Chandra, T., Woo, S. L. C., and Means, A. R. 1983. Identification of multiple species of calmodulin messenger RNA using a full length complementary DNA. J. Biol. Chem. 258:1684-1688.

Lara, M., Porta, H., Padilla, J., Folch, J., and Sánchez, F. 1984. Heterogeneity of glutamine synthetase polypeptides in Phaseolus vulgaris L. Plant Physiol. 76:1019-1023.

Lhuissier, F. G. P., de Ruijter, N. C. A., Sieberer, B. J., Esseling, J. J., and Emons, A. M. C. 2001. Time course of cell biological events evoked in legume root hair by Rhizobium Nod factors: State of the art. Ann. Bot. 87:289-302.

Line, S., and Forsen S. 1995. Determinants that govern high-affinity calcium binding. Adv. Second Messenger Phosphoprot. Res. 30:89-151.

Ling, V., and Assman, S. M. 1992. Cellular distribution of calmodulin and calmodulin-binding proteins in Vicia faba L. Plant Physiol. 100:970978.

Ling, V., Snedden, W. A., Shelp, B. J., and Assman, S. M. 1994. Analysis of a soluble calmodulin binding protein from fava bean roots: Identification of glutamate decarboxylase as a calmodulin-activated enzyme. Plant Cell 6:1135-1143.

Liu, Z., Zhu, Y., Zhao, H., Wu, Z., and Chen, Z. 1993. Cloning, sequencing, high-level expression, and activity analysis of a rice calmodulin cDNA. Asia Pac. J. Mol. Biol. Biot. 1:57-63.

Lu, Y. T., and Feldman, L. J. 1997. Light-regulated root gravitropism: A role for, and characterization of, a calcium/calmodulin-dependent protein kinase homolog. Planta 203:191-597.

Malmstrom S., Askerlund P., and Palmgren M. G. 1997. A calmodulinstimulated $\mathrm{Ca}^{2+}$-ATPase from plant vacuolar membranes with a putative regulatory domain at its N-terminus. FEBS (Fed. Eur. Biochem. Soc.) Lett. 400:324-328.

Marshak, D. R., Clarke, M., Roberts, D. M., and Watterson, D. M. 1984 Structure and functional properties of calmodulin from the eukaryotic microorganism Dyctiostelium discoideum. Biochem. 23:2891-2899.

Mathesius, U., Schlaman, H. R. M., Spaink, H. P., Sautter, C., Rolfe, B. G., and Djordjevic, M. A. 1998. Auxin transport inhibition precedes root nodule formation in white clover roots and is regulated by flavonoids and derivatives of chitin oligosaccharides. Plant J. 14:23-32.

Murray, M. G., and Thompson, W. F. 1980. Rapid isolation of high molecular weight plant DNA. Nucleic Acids Res. 8:4321-4325.

Mylona, P., Pawlowski, K., and Bisseling, T. 1995. Symbiotic nitrogen fixation. Plant Cell 7:869-885.

Narasimhulu, S. B., Kao Y. L., and Reddy A. S. 1997. Interaction of Arabidopsis Kinesin-like calmodulin-binding protein with tubulin subunits: Modulation by $\mathrm{Ca}^{2+}$-calmodulin. Plant J. 12:1139-1149.

Olwin, B. B., and Storm D. R. 1985. Calcium binding to complexes of calmodulin and calmodulin binding proteins. Biochemistry 24:80818086.

O’Neil, K. T., and DeGrado, W. F. 1990. How calmodulin binds its target : Sequence-independent recognition of amphiphilic $\alpha$-helixes. Trends Biochem. Sci. 15:59-64.

Poovahiah, B. W., and Reddy, A. S. N. 1993. Calcium signal transduction in plants. Crit. Rev. Plant Sci. 12:185-211.

Putkey, J. A., Slaugher, G. R., and Means, A. R. 1985. Bacterial expression and characterization of proteins derived from the chicken calmodulin cDNA and a calmodulin processed gene. J. Biol. Chem. 260:4704-4712.

Ramachandiran, S., Takezawa, D., Wang, W., and Poovaiah, B. W. 1997.
Functional domains of plant chimeric calcium/calmodulin-dependent protein kinase: Regulation by autoinhibitory and visinin-like domains. J. Biochem. 121:984-990.

Reli•, B., Talmont, F., Kopcinska, J., Golinowski, W., Pomé, J.-C., and Broughton, W. J. 1993. Biological activity of Rhizobium sp. NGR234 Nod-factor on Macroptillum atropurpureum. Mol. Plant-Microbe Interact. 6:764-774.

Reli•, B., Perret, X., Estrada-Garcia, M. T., Kopcinska, J., Golinowski, W., Krishnan, H. B., Pueppke, S. G., and Broughton, W. J. 1994. Nod factors of Rhizobium are a key to the legume door. Mol. Microbiol 13:171-178.

Roberts, D. M., and Harmon, A. C. 1992. Calcium-modulated proteins: Targets of intracellular calcium signals in higher plants. Annu. Rev. Plant Pysiol. Plant Mol. Biol. 43:375-414.

Satnarayan, V., and Nair, P. M. 1990. Metabolism, enzymology, and possible roles of 4-aminobutyric acid in root nodules of Medicago sativa and other nitrogen-fixing plants. Plant Sci. Lett. 29.315-326.

Schuuring, R. C., Chan, P. V., and Jones, R. L. 1996. Modulation of calmodulin mRNA and protein level in barley aleurone. Plant Physiol. 11:371-380.

Snedden, W. A., and Fromm, H. 1998. Calmodulin, calmodulin-related proteins, and plant responses to the environment. Trends Plant Sci. 3:299-304.

Stinemetz, C. L., Kuzmanoff, K. M., Evans, M. L., and Janet, H. W. 1987. Correlation between calmodulin activity and gravitropic sensitivity in primary roots of maize. Plant Physiol. 84:1337-1342.

Szymanski, D. B., Liao, B., and Zielinski, R. E. 1996. Calmodulin isoforms differentially enhance the binding of cauliflower nuclear proteins and recombinant TGA3 to a region derived from the Arabidopsis CaM3 promoter. Plant Cell 8:1067-1077.

Takezawa, D., Liu, Z. H., An, G., and Poovaiah, B. W. 1995. Calmodulin gene family in potato: Developmental and touch-induced expression of the mRNA encoding a novel isoform. Plant Mol. Biol. 27:693-703.

Vanaman, T. C. 1980. Structure, function, and evolution of calmodulin. Pages 41-58 in: Calcium and Cell Function. W. Y. Cheung, ed. Academic Press, San Diego, CA, U.S.A

Watillon, B., Kettman, R., Borus, P., and Burny, A. 1993. A calcium/calmodulin-binding serine/threonine protein kinase homologous to the mammalian type II calcium/calmodulin-dependent protein kinase is expressed in plant cells. Plant Physiol. 101:1381-1384.

Weaver C. D., Crombie, B., Stacey, G., and Roberts, D. M. 1991. Calciumdependent phosphorylation of symbiosome membrane proteins from nitrogen-fixing soybean nodules. Plant Physiol. 95:222-227.

Wymer, C., Bibikova, T. N., and Gilroy, S. 1997. Cytoplasmic free calcium distribution during the development of root hairs of Arabidopsis thaliana. Plant J. 12:427-439.

Yang, T., Lev-Yadun, S., Feldman, M., and Fromm, H. 1998. Developmentally regulated organ-, tissue-, and cell-specific expression of calmodulin genes in common wheat. Plant Mol. Biol. 37:109-120.

Yang, T., and Poovaiah, B. W. 2000. Molecular and biochemical evidence for the involvement of calcium/calmodulin in auxin action. J. Biol. Chem. 275:3137-3143.

Zielinski, R. E. 1987. Calmodulin mRNA in barley (Hordeum vulgare L.). Plant Physiol. 84:937-943.

Zielinski, R. E. 1998. Calmodulin and calmodulin-binding proteins in plants. Annu. Rev. Plant Physiol. Plant Mol. Biol. 49:697-725.

Ziengenhagen, R., and Jenissen, H. P. 1990. Plant and fungus calmodulins are polyubiquitinated at a single site in a $\mathrm{Ca}^{2+}$-dependent manner. FEBS (Fed. Eur. Biochem. Soc.) Lett. 27:253-256.

Zhou, S., and Lewis, C. 1995. Recognition and specificity in protein tyrosine kinase-mediated signaling. Trends Biochem. Sci. 20:470-475. 